\title{
A SURVEY OF THE TRENDS IN FACIAL AND EXPRESSION RECOGNITION DATABASES AND METHODS
}

\author{
Sohini Roychowdhury and Michelle Emmons \\ Department of Electrical Engineering, University of Washington, Bothell, USA
}

\begin{abstract}
Automated facial identification and facial expression recognition have topics of active research over the past few decades. Facial and expression recognition find applications in human-computer interfaces, subject tracking, real-time security surveillance systems and social networking. Several holistic and geometric methods have been developed to identify faces and expressions using public and local facial image databases. In this work we present the evolution in facial image data sets and the methodologies for facial identification and recognition of expressions such as anger, sadness, happiness, disgust, fear and surprise. We observe that most of the earlier methods for facial and expression recognition aimed at improving the recognition rates for facial feature-based methods using static images. However, the recent methodologies have shifted focus towards robust implementation of facial/expression recognition from large image databases that vary with space (gathered from the internet) and time (video recordings). The evolution trends in databases and methodologies for facial and expression recognition can be useful for assessing the next-generation topics that may have applications in security systems or personal identification systems that involve "Quantitative face" assessments.
\end{abstract}

\section{KEYWORDS}

Facial recognition, expression recognition, geometric methods, databases.

\section{INTRODUCTION}

Facial recognition has been a problem of interest since the early 1960's [1] when semi-automated methods were developed to manually locate facial features (eyes, ears, nose, mouth) followed by calculation of distances to reference points for recognition tasks. Over the next few decades facial feature detection and calculation of distances between the features and reference points became a favoured practice [2]. The first work to stray from the concept of facial feature extraction and to look at the holistic information in the residual of Eigen-faces was introduced in 1991 [3]. Since then several methodologies have been developed that analyse certain facial features or the Eigendecomposition of faces or combine both strategies [4]. The increasing number of methods for facial and expression recognition methods spurred the development of several databases that can be used for benchmarking and comparative assessment of the methodologies. Over the years, specific trends have emerged from the facial databases and the methodologies that demonstrate certain technological and computational dependencies. In this paper, we analyse past trends in the facial recognition databases and methods to assess some of the future trends in the domain of facial recognition and expression analysis.

The primary challenges associated with facial and expression recognition include variations in the following factors: lighting, pose, imaging modalities, occlusions and expressions. Other limiting factors include gender, age and complexion. Additionally, variations in image qualities due to 
data compression formats, image blurriness and variations in imaging angles impose additional constraints for automated facial and expression recognition algorithms. Two-dimensional (2D) facial recognition algorithms such as the ones in [4-8] have shown high success rate in a controlled environment, but in an uncontrolled setting their performance has been shown to drastically decrease [9]. Till date, 2D facial recognition techniques have been explored for longer than three-dimensional (3D) algorithms; nonetheless the 3D facial recognition methods have been found to be more effective in controlled and uncontrolled settings [10].

In the present day facial detection and expression recognition finds many real-time applications such as: design of human-computer interfaces, to real-time video surveillance systems, security systems [11] and expression tagging on social media [12]. With the changes in computational technologies, two categories of automated facial recognition algorithms emerged. While the first category of holistic algorithms analyses residuals in Eigen-vector decomposition of the complete facial images [13], the second category of geometric algorithms analyses specific facial features [14]. To assess the performance of all these facial recognition algorithms, several databases have been created over the years. While some data sets with images from less than 100 subjects were designed to capture the challenges in imaging angles, facial expressions and pose, larger data sets with more than 100,000 images from over 200 subjects have been designed to address the robustness constraints of automated algorithms to variations in image qualities. In this work we analyse 3 major categories of databases, based on the number of imaged subjects and the performances of well-known methods on these databases for facial and expression recognition tasks. We observe the evolution of automated algorithms from facial recognition to expression analysis, and from recognition tasks in controlled facial images to information fusion from uncontrolled video frames.

The organization of this paper is as follows. In Section 2, the categories of facial databases are presented and their evolution is discussed. In Section 3, the facial and expression recognition methods are discussed. In Section 4 concluding remarks and discussions are presented.

\section{FACial Recognition Databases}

An essential part of the constant enhancements made in the field of automated facial and expression recognition has been the collection of facial databases for benchmarking purposes. Since the 1990s there has been a drive in developing new methods for automatic face recognition as a result of the significant advances in computer and sensor technology [3-8]. Currently, there are several databases used for facial recognition which vary in size, pose, expressions, lighting conditions, occlusions and the number of imaged subjects. The earliest facial databases mostly consisted of frontal images, such as the local data set acquired from 115 subjects at Brown University used in the early works in 1987 [2]. From the year 2000 and onwards, the facial databases were seen to capture the variations in pose, lighting, imaging angles, ethnicity, gender and facial expressions [4]. Some of the most recent databases capture the variations in image sizes, compression, occlusions and are gathered from varied sources such as social media and internet [15].

Over the years, most of the well-known facial recognition algorithms have reported their performances on the databases from: AT\&T Laboratories Cambridge (formerly 'The ORL Database of Faces') [16], Facial Recognition Technology (FERET) [17], Facial Database from visions Group Essex [18], Cohn Kande AU-Coded Facial Expression Database (FE) [4], NIST Mug shot Database[19], Extended Multi Modal Verification for Teleservices and Security applications (XM2VTS) Database [20], AR Face Database from Ohio [21], Yale Face Database [22], Caltech Faces [23] and Japanese Female Facial Expression (JAFFE) Database [24]. Table 1 categorizes most of the well-known facial databases into 3 categories based on the number of 
imaged subjects. Databases that contain images from more than 200 subjects (persons) are classified as database category 1, while the databases with images from 100-200 subjects and less than 100 subjects are classified as category 2 and category 3, respectively. The details of each database are provided for each database. For instance, the AR Face Database [21], which is very well-analysed in existing literature, belongs to database category 2 since it contains a variety of images from 126 subjects (70 men, 56 women) that represent variations in expression, illumination and occlusions. This database contains over 4000 color frontal images collected over two sessions per person on 2 separate days. The diversity of images allows for it to be used by several methodologies that focus on robust facial feature detection regardless of the extent of facial occlusions due to sunglasses and scarf. Figure 1 demonstrates the variations in facial occlusions in the sample images from the AR Face Database [21].

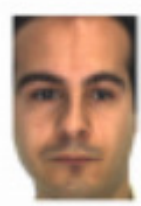

(a)

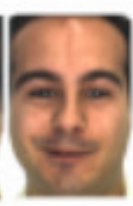

(b)

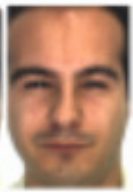

(c)

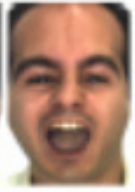

(d)

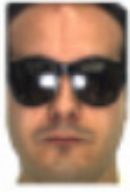

(e)

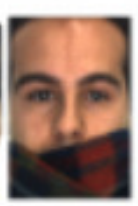

(f)

Figure 1: The six images acquired in the first session for one of the subjects in the AR face database [21] taken from the front in similar lighting conditions.

From the 3 categories of Facial Databases presented in Table 1, we observe that databases belonging to category 3 are useful for testing new methodologies on a controlled image set, while the databases from category 2 and 1 are useful for expansive parameterization of existing methods to cater to additional variations imposed by a large number of imaged subjects, imaging conditions and image formats. Also, we observe that while the early databases were focused on facial detection for subject identification, the more recent databases are geared more towards capturing the variations in imaging modalities, facial expressions, and obscurities due to makeup.

Some of the latest facial databases, not shown in Table 1, are as follows:

a. Labelled Wikipedia Faces (LWF) [25] has mined images from over 0.5 million biographic entries from the Wikipedia Living People entries and it contains 8500 faces from 1500 subjects;

b. YouTube Faces Database (YFD) [26] contains 3425 videos of 1595 different subjects (2.15 videos per subject) with video clips ranging from 48-6070 frames. This dataset was created to provide a collection of videos and labels for subject identification from videos and benchmarking video pair-matching techniques.

c. YouTube Makeup Dataset (YMD) [27] contains images from 151 subjects (Caucasian females) from YouTube makeup tutorials before and after subtle to heavy makeup is applied. 4 shots are taken for each subject ( 2 shots before and 2 shots after makeup is applied). This database has steady illumination but it demonstrates the challenges in facial recognition due to makeup alterations.

d. Indian Movie Face Database (IMFD) [28] contains 34512 images from 100 Indian actors collected from about 100 videos and cropped to include variations in pose, expression, lighting, resolution, occlusions and makeup. 
International Journal of Computer Science \& Engineering Survey (IJCSES) Vol.6, No.5, October 2015

Table 1: Categorization of Facial Databases

\begin{tabular}{|c|c|c|}
\hline Category 1: Subjects above 200 & Category 2: $100-200$ subjects & Category 3: Below 100 subjects \\
\hline \multirow[t]{2}{*}{$\begin{array}{l}\text { The BJUT-3D database [29] } \\
\text { - } 2000 \text { images, } \\
\text { - } 500 \text { distinct subjects with } 4 \\
\text { images per subject, } \\
\text { - Variations in expressions. }\end{array}$} & $\begin{array}{l}\text { Cohn- Kanade AU-Coded Facial } \\
\text { Expression Database (FE) [4] } \\
\text { - Facial action units (AUs) and } \\
\text { emotion-specified expressions, } \\
\text { - Version 1: } 486 \text { sequences from } \\
97 \text { subjects, }\end{array}$ & $\begin{array}{l}\text { The Gavab DB database [30] } \\
\text { - } 549 \text { 3-D images/facial surfaces, } \\
\text { - } 61 \text { subjects ( } 45 \text { male, } 16 \text { female), } \\
\text { - } \quad \text { images per subject, } \\
\text { pose, expression. }\end{array}$ \\
\hline & $\begin{array}{l}\text { - Up to } 100 \text { university students of } \\
\text { age range } 18-30 \text { years, } \\
\text { - Subjects were } 65 \% \text { female, } 15 \% \\
\text { African-American, } 3 \% \text { Asian or } \\
\text { Latino. }\end{array}$ & \\
\hline $\begin{array}{l}\text { The XM2VTS database [20] } \\
\text { - } 295 \text { distinct subjects, } \\
\text { - } 4 \text { recordings per subject, } \\
\text { Speaking head shot and a } \\
\text { Rotating head shot, } \\
\text { - High quality color images, } 32 \\
\text { KHz 16-bit sound files, video } \\
\text { sequences and a 3D model. }\end{array}$ & $\begin{array}{l}\text { The Basel Face Model (BFM) database } \\
\text { [31] - } 200 \text { images, } \\
\text { - } 100 \text { male, } 100 \text { female subjects, } \\
\text { - Variations in pose, illumination, } \\
\text { Generative 3D shape model } \\
\text { covering the face surface from } \\
\text { ear to ear and a high quality } \\
\text { texture model. }\end{array}$ & $\begin{array}{l}\text { The EURECOM Kinect Face database [32] } \\
\text { - } 427 \text { images, } \\
\text { - } 52 \text { subjects, } \\
\text { Variations in lighting, occlusion, } \\
\text { and } 9 \text { states of Facial } \\
\text { Expressions. }\end{array}$ \\
\hline $\begin{array}{l}\text { The FRGC database [33] } \\
\text { - } 50,000 \text { images, } \\
\text { - } 4,003 \text { subjects, } \\
\text { Uncontrolled and Controlled } \\
\text { settings, } \\
\text { Controlled Settings: } \\
\quad \text { Controlled lighting } \\
\quad \text { conditions } \\
\quad 2 \text { expressions } \\
\text { (smiling and neutral). }\end{array}$ & $\begin{array}{l}\text { The UMB database [34] } \\
\text { - } 1473 \text { total acquisitions, } \\
\text { - } 143 \text { subjects, } \\
\text { - } 4 \text { facial expressions, } \\
\text { - } \text { Facial ochd 2-D images, } \\
\text { scarves, hats, hands, eyeglasses } \\
\text { and other. }\end{array}$ & $\begin{array}{l}\text { AT\&T Laboratories Cambridge (formerly } \\
\text { 'The ORL Database of Faces) [16] } \\
\text { - } 400 \text { images, } \\
\text { - } 40 \text { subjects, } \\
\text { - Variations in lighting, } \\
\text { occlusions, facial expression. } \\
\text { - } 92 x 112 \text { pixels resolution. }\end{array}$ \\
\hline $\begin{array}{c}\text { FiA "Face-in-Action" Dataset [35] } \\
\text { - } \quad 20 \text {-second videos of face data, } \\
\text { - } 180 \text { participants mimicking a } \\
\text { passport checking scenario, } \\
\text { - Controlled, indoor environment } \\
\text { and open, outdoor environment. }\end{array}$ & $\begin{array}{l}\text { BU-3DFE (Binghamton University 3D } \\
\text { Facial Expression) [36] } \\
\text { - } 2500 \text { images, } \\
\text { - } 100 \text { subjects, } \\
\text { - Variations in expressions, } \\
\text { Ethnic/ racial ancestries. }\end{array}$ & $\begin{array}{l}\text { Japanese Female Facial Expression } \\
\text { (JAFFE) Database [JAFFE] } \\
\text { - } 213 \text { images, } \\
\text { - } 7 \text { facial expressions ( } 6 \text { basic } \\
\text { facial expressions }+1 \text { neutral), } \\
\text { - } 10 \text { Japanese female models. } \\
\text { Each image rated on } 6 \text { emotion } \\
\text { adjectives by } 60 \text { Japanese } \\
\text { subjects. }\end{array}$ \\
\hline $\begin{array}{l}\text { ND-2006 Dataset [37] } \\
\text { - } 13,450 \text { images, } \\
\text { - } 6 \text { expressions (Neutral, } \\
\text { Happiness, Sadness, Surprise, } \\
\text { Disgust, and Other). } \\
\text { - } 888 \text { subjects, } \\
\text { - Upto } 63 \text { images per subject. }\end{array}$ & $\begin{array}{l}\text { The CASIA-3D Face V1 database [38] } \\
\text { - } 4624 \text { images, } \\
\text { - } 123 \text { subjects, } \\
\text { Variations in expressions, } \\
\text { lighting and pose. }\end{array}$ & $\begin{array}{l}\text { Yale Face Database [22] } \\
\text { - } 165 \text { grayscale images. } \\
15 \text { individuals, } 11 \text { images per } \\
\text { subject. } \\
\text { One image per different facial } \\
\text { expression. } \\
\text { Configurations: center-light, } \\
\text { w/glasses, happy, left-light, w/no } \\
\text { glasses, normal, right-light, sad, } \\
\text { sleepy, surprised, and wink. }\end{array}$ \\
\hline $\begin{array}{l}\text { York 3D face database [39] } \\
\text { - Over 5000 images, } \\
\text { - } 350 \text { subjects, } \\
\text { Controlled Setting with } \\
\text { variations in lighting, pose, } \\
\text { expression. }\end{array}$ & $\begin{array}{l}\text { AR Face Database, Ohio State University } \\
\text { [21] } \\
\text { - } 4,000 \text { color images, } \\
126 \text { subjects' faces ( } 70 \text { men and } \\
56 \text { women), } \\
\text { - Images feature frontal view } \\
\text { faces, } \\
\text { - Variations facial expressions, } \\
\text { illumination conditions, and } \\
\text { occlusions (sun glasses and } \\
\text { scarf). }\end{array}$ & $\begin{array}{l}\text { MIT CBCL-Face Recognition Database } \\
\text { [40] } \\
\text { - } 10 \text { subjects. } \\
2 \text { training sets: } \\
\text { 1. High resolution pictures, } \\
\text { including frontal, half- } \\
\text { profile and profile view. } \\
\text { 2. Synthetic images } \\
\text { (324/subject) rendered from } \\
\text { 3D head models of the } 10 \\
\text { subjects. } \\
\text { - Test set consists of } 200 \text { images } \\
\text { per subject. }\end{array}$ \\
\hline
\end{tabular}




\begin{tabular}{|c|c|c|}
\hline $\begin{array}{l}\text { NIST Mugshot Identification Database } \\
\text { [19] } \\
\text { - } 1573 \text { individuals (cases) } 1495 \\
\text { male and } 78 \text { female, } \\
\text { - Front and side (profile) views, } \\
131 \text { cases with two or more } \\
\text { front views and } 1418 \text { with only } \\
\text { one front view, } \\
\text { - } 89 \text { cases with two or more } \\
\text { profiles and } 1268 \text { with only one } \\
\text { profile, } \\
27 \text { cases with two or more } \\
\text { fronts and one profile, } \\
1217 \text { cases with only one front } \\
\text { and one profile. }\end{array}$ & $\begin{array}{l}\text { The FRAV 3D database [41] } \\
\text { - } 109 \text { subjects (75 men, } \\
\text { women), } \\
\text { - } 32 \text { color captures per subject, } \\
\text { - } 320 \times 240 \text { pixel resolution, } \\
12 \text { frontal images, } 415^{\circ} \text {-turned } \\
\text { images, } 430^{\circ} \text {-turned images. } 4 \\
\text { images with gestures, } 4 \text { images } \\
\text { with occluded face features and } \\
4 \text { frontal images with a change of } \\
\text { illumination. }\end{array}$ & $\begin{array}{l}\text { The Large MPI Facial Expression database } \\
\text { [42] } \\
\text { - } 19 \text { German subjects (10 female, } \\
9 \text { male), } \\
\text { - } 55 \text { Expressions, } \\
\text { - Facial expressions available in } 3 \\
\text { repetitions, in } 2 \text { intensities and in } \\
3 \text { different camera angles. }\end{array}$ \\
\hline $\begin{array}{l}\text { Color FERET Database [17] } \\
\text { - } 1564 \text { sets of images, } \\
\text { - Total of } 14,126 \text { images, } \\
\text { - } 1199 \text { individuals and } 365 \\
\text { duplicate sets of images. }\end{array}$ & $\begin{array}{l}\text { Texas-3D Face database [43] } \\
\text { - } 1149 \text { images } \\
\text { - } 105 \text { subjects, } \\
\text { Variations in expressions, } \\
\text { gender, ethnicity }\end{array}$ & $\begin{array}{l}\text { BioID Face DB, Switzerland [50] } \\
\text { - } 1521 \text { gray level images, } \\
\text { - } 384 x 286 \text { pixel resolution, } \\
\text { - } 23 \text { test subjects, } \\
\text { Comparison reasons manually } \\
\text { set eye positions. }\end{array}$ \\
\hline $\begin{array}{l}\text { CMU Multi-PIE Face Database [44] } \\
\text { - More than } 750,000 \text { images, } \\
337 \text { people recorded in up to } \\
\text { four sessions, } \\
\text { - Subjects imaged under } 15 \text { view } \\
\text { points and 19 illumination } \\
\text { conditions, } \\
\text { - Variations in expressions, } \\
\text { - High resolution frontal images. }\end{array}$ & $\begin{array}{l}\text { The Bosphorus database [45] } \\
\text { - } 4666 \text { total acquisitions, } \\
\text { - } 105 \text { subjects, } \\
\text { - } 35 \text { facial expressions from } 6 \\
\text { basic emotions and poses, } \\
\text { - Occluded images. }\end{array}$ & $\begin{array}{l}\text { Sheffield Face (Previously UMIST) } \\
\text { database [46] } \\
\text { - } 564 \text { images, } \\
\text { - } 20 \text { subjects, } \\
\text { - Variety of poses from profile to } \\
\text { frontal views, } \\
\text { - Variety in race, gender, } \\
\text { appearance, } \\
\text { - } 220 \times 220 \text { pixels resolution in } \\
256 \text { shades of grey. }\end{array}$ \\
\hline $\begin{array}{l}\text { Face Recognition Data, University of } \\
\text { Essex, UK [18] } \\
\text { - } 395 \text { subjects (male and female), } \\
\text { - } 20 \text { images per subject, } \\
\text { - ethjects with various } \\
\text { - Majority of individuals age in } \\
\text { - } 18-20 \text { years, } \\
\text { Some individuals wearing } \\
\text { glasses and beards. }\end{array}$ & $\begin{array}{l}\text { Equinox Face Data Set [47] } \\
\text { - } 340 \text { subjects, } 3 \text { different } \\
\text { expressions, } \\
\text { - Indoor and outdoor images, } \\
\text { For each subject images } \\
\text { simultaneously acquired in } \\
\text { visible, Short Wave Infra-Red } \\
\text { (SWIR), Mid Wave Infra-Red } \\
\text { (MWIR) and Long Wave Infra- } \\
\text { Red (LWIR), } \\
\text { - } 40 \text { frame contiguous sequence. }\end{array}$ & $\begin{array}{l}\text { Caltech Faces [23] } \\
\text { - } 450 \text { face images, } \\
\text { - } 27 \text { subjects, } \\
\text { - } 896 \times 592 \text { pixels resolution, } \\
\text { Variation in lighting, } \\
\text { expressions, backgrounds. }\end{array}$ \\
\hline $\begin{array}{l}\text { FaceScrub [15] } \\
\text { - } 107,818 \text { face images of } 530 \\
\text { celebrities (265 male, } 265 \\
\text { female), } \\
\text { - } 200 \text { images per subject, } \\
\text { - Images were retrieved from the } \\
\text { Internet (uncontrolled } \\
\text { conditions). }\end{array}$ & $\begin{array}{l}\text { SCFace- Surveillance Cameras Faces } \\
\text { Database [ } 48] \\
\text { - } 4160 \text { static images (in visible } \\
\text { and infrared spectrum), } \\
\text { - } 130 \text { subjects, } \\
\text { - Images captured in uncontrolled } \\
\text { indoor conditions. }\end{array}$ & $\begin{array}{l}\text { Indian Face Database [49] } \\
\text { - } 11 \text { images from } 40 \text { distinct } \\
\text { subjects, } \\
\text { - Homogeneous background. } \\
\text { Upright and frontal position } \\
\text { images, } \\
\text { - } 640 x 480 \text { pixels resolution, } \\
\text { - Emotions: neutral, smile, } \\
\text { laughter, sad/disgust. }\end{array}$ \\
\hline
\end{tabular}

\section{FACIAL AND EXPRESSION RECOGNITION METHODS}

Several algorithms have been developed till date in the pursuit of improving the state-of-art in automated facial recognition. While the earlier methods focused on facial and expression analysis from images, recent methods have focused on video-based facial tracking. All the facial detection algorithms developed so far can be broadly classified into two categories. The first category of methods analyse the holistic faces and rely on residual images after Eigen-face decomposition for recognition tasks [3]. This category of methods, although computationally fast, are less adaptive to variations in pose, expression and image quality. The second category of geometric methods involve automated extraction of facial parts also known as Facial Action Units (FAUs) to 
compute relative distances between FAUs and their relative locations from reference points for facial and expression identification tasks [4]. These categories of methods can auto-tune to capture facial expressions in motion-based images and pose variations. However, such methods require intensive training and generally have high computation time complexities [60].

Figure 2 shows the first category Eigen-face decomposition method described in [3] that estimates Eigen-vectors corresponding to a set of holistic facial images and generates a facial signature matrix that can be further modified to identify the subjects in the images in spite of occlusions, makeup and distortions [60]. Figure 3 shows the second category method of automatically extracting FAUs for expression recognition tasks. Both these methods have been demonstrated on images from the AT\&T (ORL) Database [16].
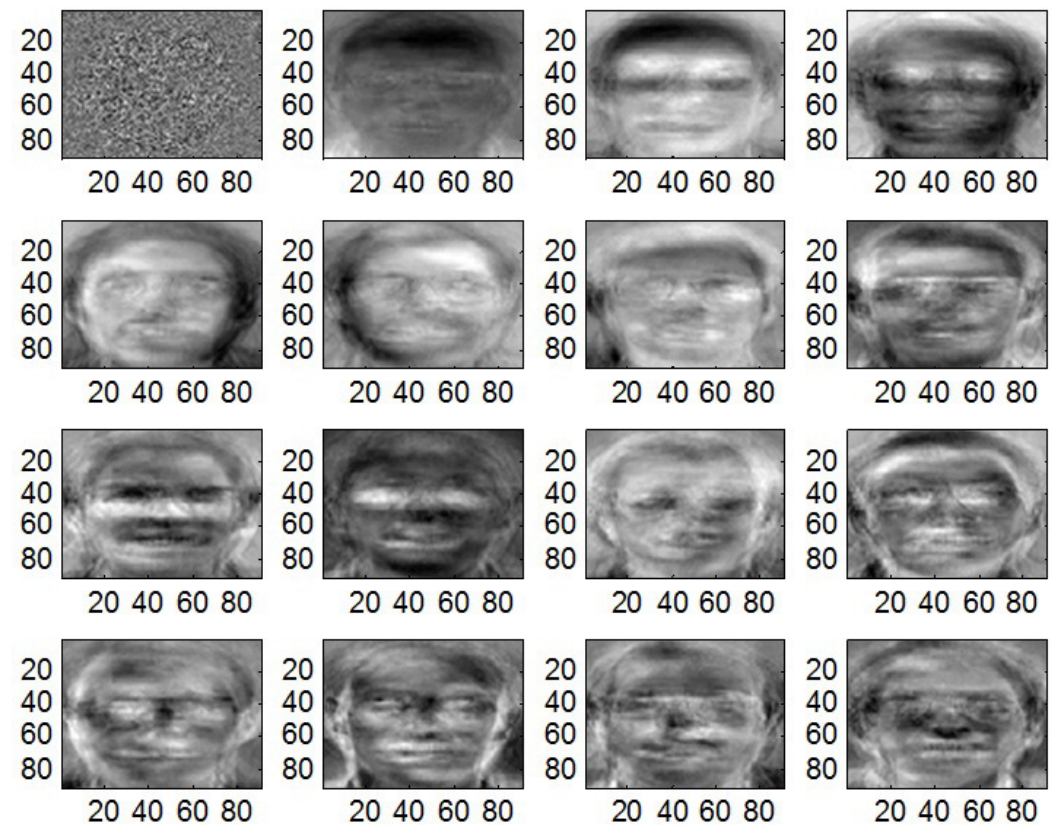

Figure 2: Example of Eigen-Face estimation using holistic facial image. The top-left image represent the averaged image or the 0th Eigen-vector. The 1st to 15th Eigen-vectors of the first image from the data base are shown thereafter.

One of the most robust algorithms for facial region detection in images is the Viola-Jones method [62] that involves Haar feature selection followed by creation of an integral image, AdaBoost classifier training and using cascaded classifiers to identify facial objects. Most of the second category of geometric methods involve the use of FAU detectors followed by classification strategies for binary or multi-class facial and expression classification tasks. Figure 4 shows an example of classification tasks involved in these FAU-based/feature-based facial recognition methods. The two classes of images have been created using images from the AT\&T (ORL) database [16]. 


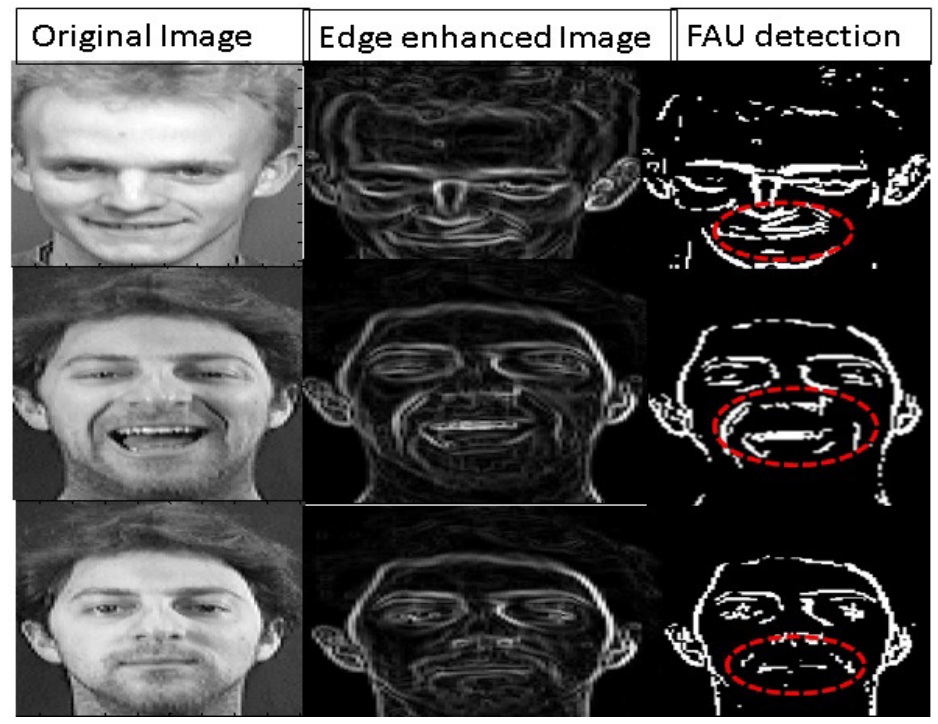

Figure 3: Example of image filtering for edge enhancement followed by automated detection of facial regions corresponding to expressions. The red circle depicts the region under analysis for "happy" expression recognition.

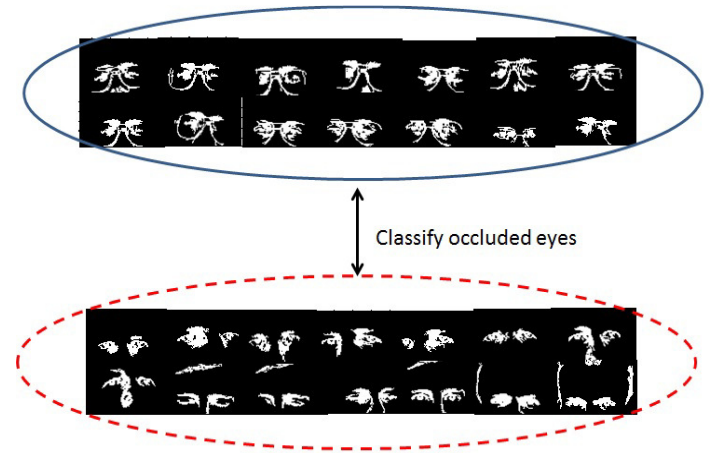

(a)

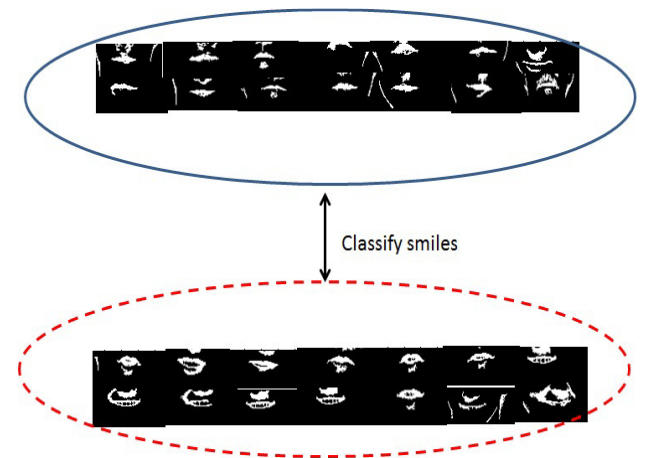

(b)

Figure 4: Example of classification tasks for facial occlusion and expression recognition. (a) Represents 2 classes of FAUs corresponding to "eye" regions in faces with glasses (occlusions) and without glasses. (b)

Represents 2 classes of FAUs with and without a "smile", for "happy" emotion recognition. A typical occlusion and emotion recognition task would involve classifier training and automated separation of these two classes of facial images.

In Table 2, the well-known methods developed for facial recognition are chronologically presented. Table 2 includes the methods, features extracted for recognition tasks, the database used, the choice of classifiers and the facial recognition rates. The six images of a single session of a subject in the AR face database [21] shown in Figure 1 is used for assessing facial recognition performance of Jia et. al. [58] in Table 2. The $\left(^{*}\right)$ symbol indicates that the same subject's duplicate picture in the second session comprises of the training/test dataset. We observe that the early methods focused on the facial pixels as features for facial recognition followed by classification tasks. More recent methods consider splitting the images into nonoverlapping regions followed by image transformation techniques for robustness to image occlusions. Classifiers such as Hidden Markov models, linear models, support vector machines and probabilistic models have been extensively used by the geometric methods [63]. 
International Journal of Computer Science \& Engineering Survey (IJCSES) Vol.6, No.5, October 2015

Table 2. Chronological Order of Well-Known Facial Recognition Methods

\begin{tabular}{|c|c|c|c|c|c|c|c|c|}
\hline $\begin{array}{l}\text { Reference } \\
\text { (Year) }\end{array}$ & $\begin{array}{l}\text { Method and } \\
\text { Features }\end{array}$ & $\begin{array}{l}\text { Classificati } \\
\text { on }\end{array}$ & Database & $\begin{array}{l}\text { Data } \\
\text { Composition }\end{array}$ & \multicolumn{3}{|c|}{$\begin{array}{l}\text { Performance } \\
\text { (Recognition Rate) } \\
(\%)\end{array}$} & Focus \\
\hline $\begin{array}{l}\text { 1. Tan et. al. } \\
\text { [51] } 2006\end{array}$ & $\begin{array}{l}\text { The training } \\
\text { and test faces } \\
\text { are } \\
\text { disintegrated } \\
\text { into sub-blocks } \\
\text { followed by } \\
\text { Self } \\
\text { Organizing } \\
\text { Maps (SOM) } \\
\text { embedding } \\
\text { using a Partial } \\
\text { Distance (PD) } \\
\text { metric and } \\
\text { selecting the } \\
\text { smallest } \\
\text { distance face as } \\
\text { the true } \\
\text { identity. }\end{array}$ & $\begin{array}{l}\text { Part-based } \\
\text { nonmetric } \\
\text { distance } \\
\text { learning } \\
\text { method that } \\
\text { partitions } \\
\text { facial } \\
\text { images into } \\
\text { non- } \\
\text { overlapping } \\
\text { blocks, } \\
\text { computes } \\
\text { PD and } \\
\text { performs } \\
\text { SOM } \\
\text { embedding } \\
\text { to recognize } \\
\text { identity of a } \\
\text { test face. }\end{array}$ & $\begin{array}{l}\text { i)AT\&T } \\
\text { (ORL) } \\
{[16]} \\
\text { ii) AR } \\
\text { Face } \\
\text { Database } \\
\text { [21] }\end{array}$ & $\begin{array}{l}\text { Training: } \\
\text { i)700 in AR } \\
\text { dataset } \\
\text { ii)5 images/ } \\
\text { subject in } \\
\text { ORL dataset } \\
\text { Testing: } \\
\text { i) } 1900 \text { in AR } \\
\text { dataset } \\
\text { ii)5 } \\
\text { images/subject } \\
\text { in ORL dataset } \\
\text { Resized } \\
\text { Image } \\
\text { Resolution: } \\
\text { AR Face- } \\
\text { [66x48] } \\
\text { AT\&T(ORL)- } \\
\text { [112x92] }\end{array}$ & \multicolumn{3}{|c|}{$\begin{array}{l}\text { AR Face: } 97 \% \\
\text { ORL Dataset: } 74.6 \%\end{array}$} & $\begin{array}{l}\text { Recognition } \\
\text { with } \\
\text { occlusion }\end{array}$ \\
\hline $\begin{array}{l}\text { 2. Liu et. al. } \\
\text { [52] } 2006\end{array}$ & $\begin{array}{l}\text { Images are } \\
\text { represented by } \\
\text { similarity } \\
\text { features to } \\
\text { reference set } \\
\text { for a relative } \\
\text { matching } \\
\text { strategy. }\end{array}$ & $\begin{array}{l}\text { Generalizati } \\
\text { on of Kernel } \\
\text { discriminant } \\
\text { Analysis } \\
\text { (KDA), } \\
\text { Linear } \\
\text { Discriminan } \\
\text { t Analysis } \\
\text { (LDA) }\end{array}$ & $\begin{array}{l}\text { FERET } \\
\text { database } \\
{[17]}\end{array}$ & $\begin{array}{l}\text { Training: } \\
1002 \text { front } \\
\text { view face } \\
\text { images } \\
\text { selected from } \\
\text { training } \\
\text { Testing: } \\
\text { FA has } 1196 \\
\text { subjects and } \\
\text { the FB set has } \\
1195 \text { subjects. }\end{array}$ & \multicolumn{3}{|c|}{$97.41 \%$} & $\begin{array}{l}\text { Handles } \\
\text { nonlinear } \\
\text { variations, } \\
\text { especially } \\
\text { occlusion }\end{array}$ \\
\hline \multirow[t]{4}{*}{$\begin{array}{l}\text { 3. Oh et. al. } \\
\text { [53] } \\
\text { Kim et. al. [54] } \\
(2006-2007)\end{array}$} & \multirow{4}{*}{$\begin{array}{l}\text { Two phase } \\
\text { method: } \\
\text { Occlusion } \\
\text { detection phase } \\
\text { followed by } \\
\text { Selective local } \\
\text { non-negative } \\
\text { matrix } \\
\text { factorization } \\
\text { phase. Each } \\
\text { face is divided } \\
\text { into non- } \\
\text { overlapping } \\
\text { patches } \\
\text { represented by } \\
\text { principal } \\
\text { component } \\
\text { analysis } \\
\text { (PCA). The } \\
\text { non-occluded } \\
\text { patches are } \\
\text { used for } \\
\text { classification in } \\
\text { PCA space. } \\
\text { Occlusions are } \\
\text { detected by } \\
\text { combined k- } \\
\text { nearest } \\
\text { neighbor } \\
\text { (kNN) and 1- } \\
\text { nearest } \\
\text { Neighbor (NN) }\end{array}$} & \multirow{4}{*}{$\begin{array}{l}\text { Partial } \\
\text { matching of } \\
\text { non- } \\
\text { occluded } \\
\text { image parts } \\
\text { in the PCA } \\
\text { patch space } \\
\text { performed } \\
\text { by following } \\
3 \text { methods. } \\
\text { a) Using } \\
\text { projection of } \\
\text { each image } \\
\text { row in 2-D } \\
\text { PCS } \\
\text { subspace. } \\
\text { b) } \\
\text { Partitioning } \\
\text { each face to } \\
6 \text { non- } \\
\text { overlapping } \\
\text { blocks ( } 3 \text { on } \\
\text { left, } 3 \text { on } \\
\text { right) and } \\
\text { projecting } \\
\text { them on } \\
\text { PCA sub- } \\
\text { space. } \\
\text { c) Image } \\
\text { transformati } \\
\text { on followed } \\
\text { by }\end{array}$} & \multirow[t]{4}{*}{$\begin{array}{l}\text { AR-face } \\
\text { Database } \\
\text { (76 men, } \\
59 \\
\text { women) } \\
{[21]}\end{array}$} & \multirow{4}{*}{$\begin{array}{l}\text { Training: } \\
\text { i) } 35 \text { sunglass } \\
\text { images. } \\
\text { ii) } 35 \text { scarf } \\
\text { images } \\
\text { from } 20 \\
\text { men and } 15 \\
\text { women. } \\
\text { Testing: } \\
\text { i) } 100 \text { sunglass } \\
\text { images } \\
\text { ii) } 100 \text { scarf } \\
\text { images. }\end{array}$} & $\begin{array}{l}\text { types } \\
\text { of } \\
\text { occlu } \\
\text { sions }\end{array}$ & scarf & $\begin{array}{l}\text { s } \\
\text { u } \\
\mathrm{n} \\
- \\
\mathrm{g} \\
\mathrm{l} \\
\mathrm{a} \\
\mathrm{s} \\
\mathrm{s} \\
\mathrm{e} \\
\mathrm{s}\end{array}$ & $\begin{array}{l}\text { Facial } \\
\text { recognition } \\
\text { with } \\
\text { occlusions }\end{array}$ \\
\hline & & & & & $\begin{array}{l}\text { Meth } \\
\text { od a) }\end{array}$ & $99 \%$ & $\begin{array}{l}9 \\
8 \\
\% \\
\end{array}$ & \\
\hline & & & & & $\begin{array}{l}\text { Meth } \\
\text { od b) }\end{array}$ & $98 \%$ & $\begin{array}{l}9 \\
6 \\
\%\end{array}$ & \\
\hline & & & & & $\begin{array}{l}\text { Meth } \\
\text { od c) }\end{array}$ & $98 \%$ & $\begin{array}{l}9 \\
8 \\
\%\end{array}$ & \\
\hline
\end{tabular}


International Journal of Computer Science \& Engineering Survey (IJCSES) Vol.6, No.5, October 2015

\begin{tabular}{|c|c|c|c|c|c|c|c|c|}
\hline & $\begin{array}{l}\text { threshold } \\
\text { classifier. }\end{array}$ & $\begin{array}{l}\text { projection of } \\
\text { each row in } \\
\text { PCA sub- } \\
\text { space. }\end{array}$ & & & & & & \\
\hline \multirow[t]{3}{*}{$\begin{array}{l}\text { 4. Zhang et. al. } \\
\text { [55] } \\
2007\end{array}$} & \multirow{3}{*}{$\begin{array}{l}\text { Each face is } \\
\text { represented by } \\
\text { local Gabor } \\
\text { binary patterns } \\
\text { (LGBP) } \\
\text { converted into } \\
\text { a feature } \\
\text { vector. Using } \\
\text { Kullback- } \\
\text { Leibler } \\
\text { Divergence } \\
\text { (KLD) distance } \\
\text { between LGBP } \\
\text { features, the } \\
\text { probability of } \\
\text { occlusions is } \\
\text { estimated. } \\
\text { Occlusion } \\
\text { probability is } \\
\text { the weight for } \\
\text { feature } \\
\text { matching. }\end{array}$} & \multirow{3}{*}{$\begin{array}{l}\text { Thresholded } \\
\text { occlusion } \\
\text { probability } \\
\text { computed } \\
\text { using the } \\
\text { KLD } \\
\text { distance } \\
\text { metric is } \\
\text { used for } \\
\text { classificatio } \\
\text { n. }\end{array}$} & \multirow[t]{3}{*}{$\begin{array}{l}\text { AR face } \\
\text { database } \\
{[21]}\end{array}$} & \multirow{3}{*}{$\begin{array}{l}\text { Training: } \\
50,[80 \times 88] \\
\text { resized by } \\
\text { position of } \\
\text { eyes randomly } \\
\text { chosen } \\
\text { subjects with } \\
\text { neutral } \\
\text { expression. } \\
\text { Testing: } \\
\text { Synthetic } \\
\text { occlusions } \\
\text { added to } \\
\text { neutral, } \\
\text { smiling, } \\
\text { screaming and } \\
\text { angry faces. }\end{array}$} & $\begin{array}{l}\text { Imag } \\
\text { ed } \\
\text { Sessi } \\
\text { on }\end{array}$ & $\begin{array}{l}\text { Sungl } \\
\text { asses }\end{array}$ & $\begin{array}{l}\text { S } \\
c \\
a \\
r \\
\text { f }\end{array}$ & \multirow[t]{3}{*}{$\begin{array}{l}\text { Recognition } \\
\text { with } \\
\text { occlusion }\end{array}$} \\
\hline & & & & & 1 & $84 \%$ & $\begin{array}{l}1 \\
0 \\
0 \\
\% \\
\end{array}$ & \\
\hline & & & & & 2 & $80 \%$ & $\begin{array}{l}9 \\
6 \\
\%\end{array}$ & \\
\hline \multirow[t]{3}{*}{$\begin{array}{l}\text { 5. Lin et. al. } \\
{[56]} \\
2008\end{array}$} & \multirow{3}{*}{$\begin{array}{l}\text { Posterior union } \\
\text { model } \\
\text { decision-based } \\
\text { neural network } \\
\text { (PUDBNN). } \\
\text { Posterior union } \\
\text { model (PUM) } \\
\text { ignores } \\
\text { severely } \\
\text { mismatched } \\
\text { features and } \\
\text { focusses on } \\
\text { matched local } \\
\text { features. Partial } \\
\text { distortions are } \\
\text { simulated by } \\
\text { adding } \\
\text { sunglasses, } \\
\text { beards (male) } \\
\text { and scarf } \\
\text { (female). }\end{array}$} & \multirow{3}{*}{$\begin{array}{l}\text { Local } \\
\text { Features } \\
\text { comprise of } \\
3 \text { level db4 } \\
\text { wavelet } \\
\text { transform. } \\
\text { Each face } \\
\text { represented } \\
\text { by } 25 \\
\text { coefficients } \\
\text { as local } \\
\text { features. } \\
\text { Neural } \\
\text { Networks } \\
\text { classifier } \\
\text { performs } \\
\text { facial } \\
\text { recognition } \\
\text { decision. }\end{array}$} & \multirow{3}{*}{$\begin{array}{l}\text { XM2VTS } \\
\text { [20] and } \\
\text { AT\&T } \\
\text { (ORL) } \\
\text { Database } \\
\text { s [16]. }\end{array}$} & \multirow{3}{*}{$\begin{array}{l}\text { XM2VTS: } \\
100 \text { subjects } \\
\text { selected } \\
\text { randomly with } \\
4 \text { images per } \\
\text { subject. } \\
\text { Training: } 3 \\
\text { images per } \\
\text { subject. } \\
\text { Testing: } 1 \\
\text { image per } \\
\text { subject. } \\
\text { AT\&T: } 40 \\
\text { subjects with } \\
\text { 10 images per } \\
\text { subject. } \\
\text { Training: } 5 \\
\text { images per } \\
\text { subject. } \\
\text { Testing: } 5 \\
\text { images per } \\
\text { subject. }\end{array}$} & $\begin{array}{l}\text { Data } \\
\text { base }\end{array}$ & \multirow{2}{*}{\multicolumn{2}{|c|}{$\begin{array}{l}\text { Average } \\
\text { Recognitio } \\
\text { n Rate } \\
83.5 \%\end{array}$}} & \multirow{3}{*}{$\begin{array}{l}\text { Recognition } \\
\text { with } \\
\text { occlusion and } \\
\text { unknown } \\
\text { partial } \\
\text { distortions. }\end{array}$} \\
\hline & & & & & ORL & & & \\
\hline & & & & & $\begin{array}{l}\text { XM2 } \\
\text { VTS }\end{array}$ & \multicolumn{2}{|l|}{$82.4 \%$} & \\
\hline \multirow[t]{3}{*}{$\begin{array}{l}6 . \\
\text { Guo et, al. [57] } \\
\text { Jia et. al. [58] } \\
(2001-2009)\end{array}$} & \multirow{3}{*}{$\begin{array}{l}\text { Partial Support } \\
\text { Vector } \\
\text { Machines } \\
\text { (PSVM) } \\
\text { criterion is } \\
\text { introduced to } \\
\text { work with } \\
\text { missing feature } \\
\text { components. } \\
\text { Features } \\
\text { comprise of } \\
\text { facial pixel } \\
\text { values. The } \\
\text { goal is to } \\
\text { minimize } \\
\text { probability of } \\
\text { overlap } \\
\text { between most } \\
\text { probable values }\end{array}$} & \multirow{3}{*}{$\begin{array}{l}\text { PSVM } \\
\text { classificatio } \\
\mathrm{n} \text { enables } \\
\text { training and } \\
\text { testing for } \\
\text { facial } \\
\text { recognition } \\
\text { on occluded } \\
\text { and non- } \\
\text { occluded } \\
\text { faces. The } \\
\text { occlusions } \\
\text { are } \\
\text { artificially } \\
\text { added to } \\
\text { training } \\
\text { images by } \\
\text { overlaying } \\
\text { [sxs] pixels }\end{array}$} & \multirow[t]{3}{*}{$\begin{array}{l}\text { AR face } \\
\text { database } \\
{[21] \text { and }} \\
\text { FRGC } \\
\text { version } 2 \\
\text { dataset } \\
{[33]}\end{array}$} & \multirow{3}{*}{$\begin{array}{l}\text { AR Database: } \\
1200 \text { images. } \\
\text { Images are } \\
\text { cropped and } \\
\text { resized to } \\
\text { [29×21] pixels } \\
\text { FRGC } \\
\text { version } 2 \\
\text { dataset: } \\
800 \text { images. } \\
\text { Images are } \\
\text { cropped and } \\
\text { resized to } \\
\text { [30×26] } \\
\text { pixels. } \\
\text { Cropping and } \\
\text { resizing }\end{array}$} & $\begin{array}{l}\text { Imag } \\
\text { es in } \\
\text { Train } \\
\text { ing } \\
\text { sets } \\
\text { (refer } \\
\text { to } \\
\text { Figur } \\
\text { e 1) }\end{array}$ & $\begin{array}{l}\text { Image } \\
\mathrm{s} \text { in } \\
\text { Testin } \\
\mathrm{g} \text { sets } \\
\text { (refer } \\
\text { to } \\
\text { Figur } \\
\text { e 1) }\end{array}$ & $\begin{array}{l}\mathrm{R} \\
\mathrm{e} \\
\mathrm{s} \\
\mathrm{u} \\
\mathrm{lt}\end{array}$ & \multirow[t]{3}{*}{$\begin{array}{l}\text { Recognition } \\
\text { with random } \\
\text { occlusions. }\end{array}$} \\
\hline & & & & & $\begin{array}{l}{[\mathrm{a}, \mathrm{e},} \\
\mathrm{f}]\end{array}$ & $\begin{array}{l}{[\mathrm{b}, \mathrm{c},} \\
\mathrm{d}]\end{array}$ & $\begin{array}{l}8 \\
8\end{array}$ & \\
\hline & & & & & $\begin{array}{l}{\left[a^{*},\right.} \\
e^{*} \\
\left.f^{*}\right]\end{array}$ & $\begin{array}{l}{\left[b^{*},\right.} \\
c^{*} \\
\left.d^{*}\right]\end{array}$ & $\begin{array}{l}9 \\
0\end{array}$ & \\
\hline
\end{tabular}


International Journal of Computer Science \& Engineering Survey (IJCSES) Vol.6, No.5, October 2015

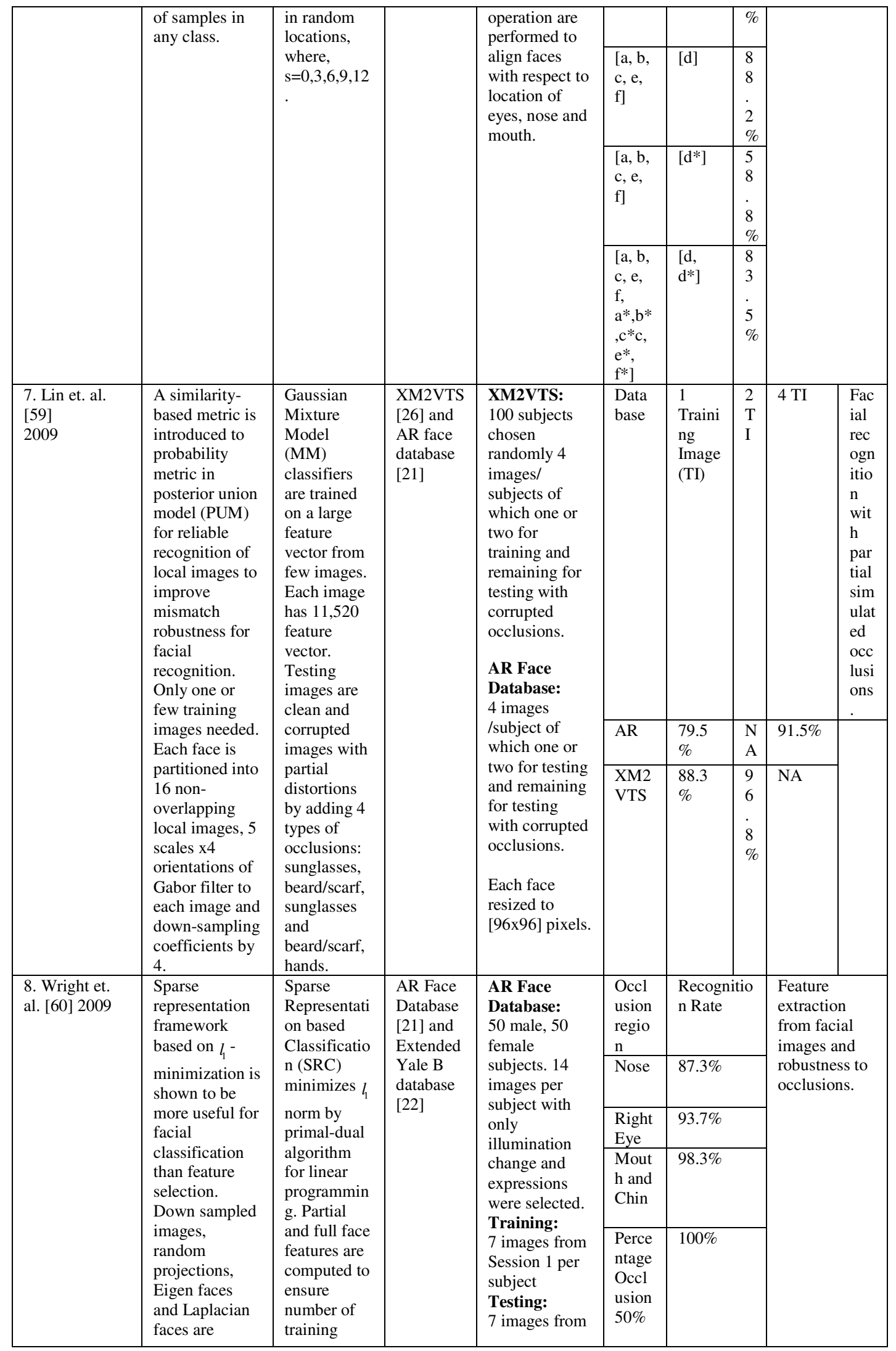


International Journal of Computer Science \& Engineering Survey (IJCSES) Vol.6, No.5, October 2015

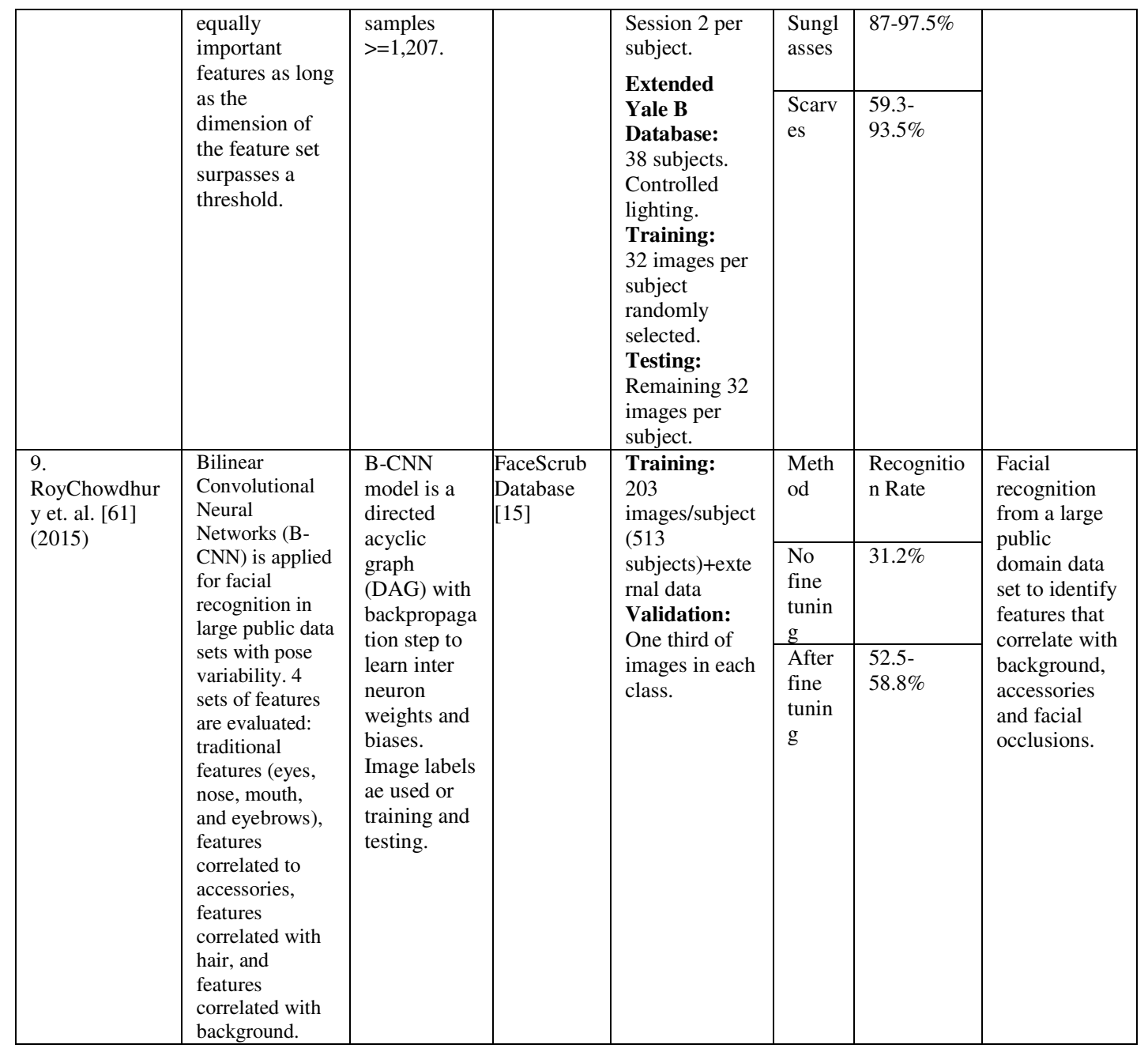

In Table 3, the chronological development in facial expression recognition methods is shown. Here, we observe that the early methods involved extraction of facial action units (AUs) from images for automated expression recognition algorithms for expressions such as anger, disgust, sadness, happy, surprise. Recent methods focus on expression analysis rom video recordings and variations in training and test data sets.

Some methods that perform automated facial and expression recognition on the recent data bases mentioned in Section 2 are as follows:

a. Dago-Cass et. al. [73] (2011): Gender classification is performed using appearance based, feature based (Gabor coefficients and local binary patterns) descriptors with linear SVM and discriminant analysis. 60-94\% recognition rates are achieved on the LFW database [25].

b. Wolf et. al. [26] (2011): Facial recognition in unconstrained video with matched background similarity is performed. The SVM classifier is used on a data set comprising of 1 video for 591 subjects, 2 videos for 471 subjects, 3 videos for 307 subjects, 4 videos for 167 subjects, 5 videos for 51 subjects and 6 videos for 8 subjects. 50-77\% recognition rates are achieved on the YF database [26].

c. Chen et. al. [27] (2013): Shape, texture, color of images with and without makeup are used for facial recognition tasks (1484 features). Geometric features corresponding to certain regions of the face (such as eyes, mouth) are extracted followed by classification by SVM and AdaBoost. Recognition rates for facial AUs and full face lie in the range 58-91\% on the YM database [27]. 
International Journal of Computer Science \& Engineering Survey (IJCSES) Vol.6, No.5, October 2015

d. Beham et. al. [74] (2014): Dictionary-based approach to extract features and perform k-means clustering with sparse representation. The images from the IMFD [28], CMU Pie [44] and Extended Yale B [22] datasets have variations in illumination, expression and controlled/uncontrolled settings. The expressions are captured by rotation invariant local binary patterns and histogram of gradients.

Sarode et. al. [75] (2014): Automated facial recognition from video frames with variations in pose and appearance is performed. Modified Genetic Algorithm (GA) based transfer vectors are used for generating facial features from different poses. Classification is performed by knearest neighbor (k-NN) and discriminant analysis on the FERET database [17] and an unconstrained database created similar to IMFD [28]. Recognition rate ranges from 1291.81\% for FERET Database [17] and $6.55-25.32 \%$ for the unconstrained database.

Kumar et. al. [76] (2014): Sparse framework with $1_{1}$-minimization is used for facial recognition in the IMFD [28] database for robustness to age, illumination, pose, expression, lighting and storage limitations in images extracted from videos. Two kinds of features are extracted: Scale invariant feature transform (SIFT) and local binary patterns. The features are reduced by performing principal component analysis (PCA) followed by supervised classification using k-NN and sparse representation classifier. For images in IMFD [28] (with at least 200 images per subject) from each of the 100 subjects, 100 images are used for training and the rest are used for testing. Recognition rates in the range 55-69\% are achieved.

\section{CONCLUSIONS AND Discussion}

Over the past few decades facial and expression recognition topics have been significantly analyzed and there have been significant changes in the innovation trends. While early methods focused on semi-automated facial recognition, the later methods shifted focus to develop fully automated facial recognition methods that are robust to pose, illumination, imaging/lighting limitations, occlusions and expressions. To facilitate comparative assessment between methods, several public data bases evolved to capture the limitations of automated facial recognition. This facilitated significant analysis of robust methods that extracted holistic facial features and geometric action units (AUs) from faces for facial recognition in the event of occlusions. Thereafter, the focus of methods shifted to automated facial expression recognition, where expressions could vary as neutral, happy, sad, surprise, anger and disgust. This caused a shift in the trend of the public databases that began to be focused on subject level expression detection.

Automated age, ethnicity and gender detection methods and databases were also developed, but they were not as significantly analysed as the automated expression recognition problem. The most recent trends have further moved towards automated facial and expression recognition from images that vary over time (video recordings) and images that vary over space (collected from the internet). This caused a shift of focus to methods that are independent of image storage and compression limitations. Some of the well-known recent databases collect images from videos in the internet and they represent a wide variation in image storage and quality [15] [25-28]. This motivates further research into scalable cloud-based methods that can extract features from large databases and correlate them with facial recognition tasks. Thus, future trends may involve automated robust facial/expression recognition in video streams that vary over space (e.g. auto-tagging of subjects as they age from video recordings gathered over the internet).

In this work we categorize the well-known facial and expression recognition databases based on the number of subjects imaged. While the databased with images from lesser number of subjects can be useful for applications involving facial and expression recognition in limited/controlled settings, the databases with large number of subjects can be useful for background equalization, and recognition tasks on images with uncontrolled imaging parameters. Further, the analysis of facial recognition and facial expression recognition methods shows that facial expression and occlusions pose a bigger challenge to robust automated facial and expression recognition methods than gender, ethnicity and age of subjects. 
International Journal of Computer Science \& Engineering Survey (IJCSES) Vol.6, No.5, October 2015

Table 3: Chronological Order of Facial Expression Recognition Methods

\begin{tabular}{|c|c|c|c|c|c|c|c|}
\hline $\begin{array}{l}\text { Reference } \\
\text { (Year) }\end{array}$ & Method & $\begin{array}{l}\text { Features and } \\
\text { Classification }\end{array}$ & Database & $\begin{array}{l}\text { Data } \\
\text { Composition }\end{array}$ & \multicolumn{2}{|c|}{$\begin{array}{l}\text { Performance } \\
\text { (Recognition } \\
\text { Rate) }\end{array}$} & Properties \\
\hline $\begin{array}{l}\text { 1. Tian et. al. } \\
\text { [4] } \\
(2001)\end{array}$ & $\begin{array}{l}\text { Automatic Face } \\
\text { Analysis } \\
\text { (AFA) system } \\
\text { based on } \\
\text { permanent } \\
\text { facial features } \\
\text { (brows, eyes, } \\
\text { mouth) and } \\
\text { transient facial } \\
\text { features (facial } \\
\text { furrow depths) } \\
\text { in a frontal- } \\
\text { view face } \\
\text { image } \\
\text { sequences. } \\
\text { Recognition of } \\
\text { 16-30 facial } \\
\text { action units } \\
\text { (AUs). }\end{array}$ & $\begin{array}{l}2 \text { artificial } \\
\text { neural } \\
\text { networks } \\
\text { (ANN) for: } \\
\text { i) upper face } \\
\text { recognition } \\
\text { ii) lower face } \\
\text { recognition. } \\
\text { Permanent } \\
\text { Features: } \\
\text { Optical Flow, } \\
\text { Gabor } \\
\text { Wavelets and } \\
\text { Multi-State } \\
\text { Models. } \\
\text { Transient } \\
\text { Features: } \\
\text { Canny Edge } \\
\text { Detection }\end{array}$ & $\begin{array}{l}\text { Cohn- } \\
\text { Kanad } \\
\text { e [4] } \\
\text { and } \\
\text { Ekman } \\
\text {-Hager } \\
\text { [5] }\end{array}$ & $\begin{array}{l}\text { Upper Face: } \\
50 \text { sample } \\
\text { sequences } \\
\text { from } 14 \\
\text { subjects } \\
\text { performing } 7 \\
\text { AUs. } \\
\text { Lower Face: } \\
63 \text { sample } \\
\text { sequences } \\
\text { from } 32 \\
\text { subjects } \\
\text { performing } \\
11 \text { AUs. }\end{array}$ & \multicolumn{2}{|c|}{$\begin{array}{l}\text { Average } \\
\text { Recognition rate } \\
\text { upper face } \\
96.4 \% \text { AUs } \\
\text { (95.4\% excluding } \\
\text { neutral } \\
\text { expression) and } \\
\text { Lower face } \\
96.7 \% \text { AUs } \\
\text { (95.6\% excluding } \\
\text { neutral } \\
\text { expression) }\end{array}$} & $\begin{array}{l}\text { Real-time system } \\
\text { recognizes posed } \\
\text { expressions of } \\
\text { happiness, } \\
\text { surprise, anger, } \\
\text { fear. Motion is } \\
\text { invariant to } \\
\text { scaling. Uses } \\
\text { facial feature } \\
\text { tracker to reduce } \\
\text { processing time. }\end{array}$ \\
\hline $\begin{array}{l}\text { 2. Tan et. al. } \\
{[64]} \\
2005\end{array}$ & $\begin{array}{l}\text { Self-organizing } \\
\text { map (SOM) is } \\
\text { used to learn } \\
\text { the subspace } \\
\text { occupied by } \\
\text { each facial } \\
\text { image. Next, } \\
\text { soft k-nearest } \\
\text { neighbor } \\
\text { (kNN) } \\
\text { classifier is } \\
\text { used to } \\
\text { recognize facial } \\
\text { identity. }\end{array}$ & $\begin{array}{l}\text { Image divided } \\
\text { into non- } \\
\text { overlapping } \\
\text { blocks of } \\
\text { equal size. } \\
\text { Local face } \\
\text { features } \\
\text { extracted from } \\
\text { the image sub- } \\
\text { blocks, Eigen- } \\
\text { faces and } \\
\text { Gabor filtered } \\
\text { sub-images. } \\
\text { The k-NN } \\
\text { classifier } \\
\text { outputs a } \\
\text { confidence } \\
\text { vector with } \\
\text { highest degree } \\
\text { of support for } \\
\text { the most } \\
\text { probable facial } \\
\text { feature vector }\end{array}$ & $\begin{array}{l}\text { AR } \\
\text { databa } \\
\text { se [21] } \\
\text { and } \\
\text { FERE } \\
\text { T } \\
\text { databa } \\
\text { se [17] }\end{array}$ & $\begin{array}{l}\text { AR Database: } \\
100 \text { subjects } \\
\text { (50 male, } 50 \\
\text { female). } \\
\text { Training: } \\
\text { Neutral } \\
\text { expression } \\
\text { from } 100 \\
\text { subjects } \\
\text { Testing: } \\
\text { Smile, anger, } \\
\text { scream } \\
\text { expression } \\
\text { from 100 } \\
\text { subjects. } \\
\text { FERET } \\
\text { Database: } \\
1196 \\
\text { subjects (1 } \\
\text { image/subjec } \\
\text { t) } \\
\text { Probed } \\
\text { training and } \\
\text { testing. }\end{array}$ & \multicolumn{2}{|c|}{$\begin{array}{l}\text { Facial } \\
\text { Recognition: 64- } \\
100 \% \\
\text { With variations } \\
\text { in expression, } \\
\text { and occlusions. }\end{array}$} & $\begin{array}{l}\text { Automated facial } \\
\text { recognition with } \\
\text { partial occlusions } \\
\text { and varying } \\
\text { expression }\end{array}$ \\
\hline \multirow{6}{*}{$\begin{array}{l}\text { 3. Faltemier } \\
\text { et. al. } \\
\text { [37] } \\
2007\end{array}$} & \multirow{6}{*}{$\begin{array}{l}\text { Multi-Instance } \\
\text { Enrollment } \\
\text { Representation } \\
\text { for 3-D Face } \\
\text { Recognition. } \\
\text { Using 3-D } \\
\text { shape of frontal } \\
\text { view face, up to } \\
28 \text { regions are } \\
\text { detected and } \\
\text { aligned using } \\
\text { iterative closest } \\
\text { point } \\
\text { registration } \\
\text { (ICP) } \\
\text { algorithm. }\end{array}$} & \multirow{6}{*}{$\begin{array}{l}\text { Accuracy of } \\
\text { nose-tip image } \\
\text { determines } \\
\text { expression } \\
\text { recognition } \\
\text { rate. ICP } \\
\text { iterates till } \\
\text { root mean } \\
\text { square (RMS) } \\
\text { scores }<0.0001 \\
\text { or } 100 \\
\text { iterations. For } \\
\text { good initial } \\
\text { alignment } \\
\text { iterations } \\
\text { needed=30. }\end{array}$} & \multirow{6}{*}{$\begin{array}{l}\text { ND- } \\
2006 \\
\text { data } \\
\text { corpus } \\
(3 D) \\
{[37]}\end{array}$} & \multirow{6}{*}{$\begin{array}{l}888 \text { subjects } \\
\text { with up to } 63 \\
\text { images/subject } \\
\text { 13,450 images } \\
\text { containing } 6 \\
\text { different types } \\
\text { of expressions } \\
\text { \{Neutral: } 9899 \\
\text { images, } \\
\text { Happiness: } \\
\text { 2230 images, } \\
\text { Sadness: } 180 \\
\text { images, } \\
\text { Surprise: } 389 \\
\text { images, } \\
\text { Disgust: } 205 \\
\text { images, } \\
\text { Other: } 557 \\
\text { images }\}\end{array}$} & $\begin{array}{l}\text { Expr } \\
\text { essio } \\
\text { ns }\end{array}$ & $\begin{array}{l}\text { Recogni } \\
\text { tion } \\
\text { Rate }\end{array}$ & \multirow{6}{*}{$\begin{array}{l}\text { Expression } \\
\text { Recognition. } \\
\text { Heterogeneous } \\
\text { expression } \\
\text { sampling } \\
\text { improves } \\
\text { recognition rate. }\end{array}$} \\
\hline & & & & & $\begin{array}{l}\text { Neut } \\
\text { ral+ } \\
\text { Happ } \\
\text { y+Sa } \\
\text { d+Su } \\
\text { rpris } \\
\text { e }\end{array}$ & $98 \%$ & \\
\hline & & & & & $\begin{array}{l}\text { Neut } \\
\text { ral }\end{array}$ & $82.8 \%$ & \\
\hline & & & & & $\begin{array}{l}\text { Happ } \\
\mathrm{y}\end{array}$ & $85.1 \%$ & \\
\hline & & & & & Sad & $91 \%$ & \\
\hline & & & & & $\begin{array}{l}\text { Surp } \\
\text { rise }\end{array}$ & $89.8 \%$ & \\
\hline
\end{tabular}


International Journal of Computer Science \& Engineering Survey (IJCSES) Vol.6, No.5, October 2015




International Journal of Computer Science \& Engineering Survey (IJCSES) Vol.6, No.5, October 2015

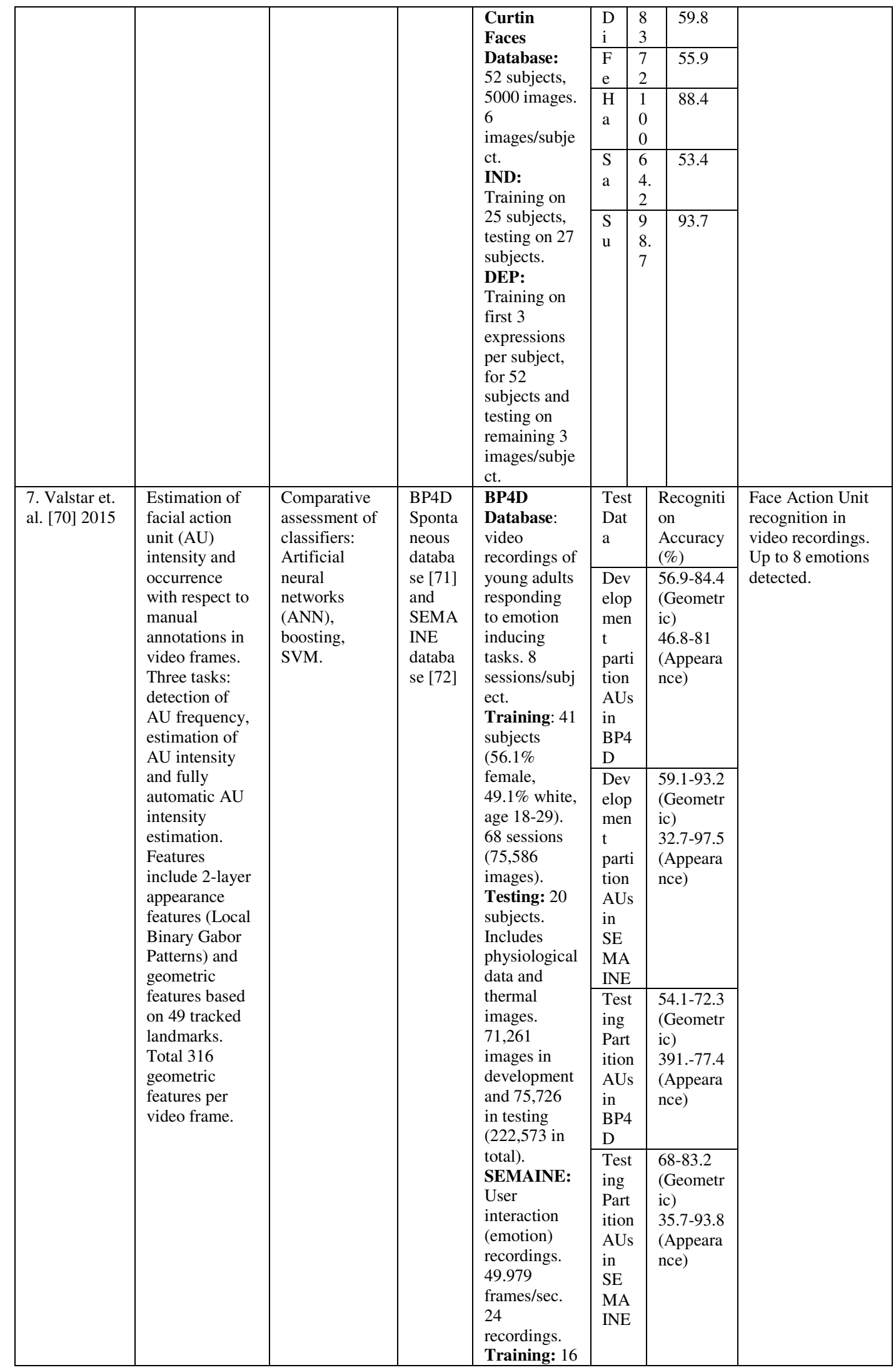




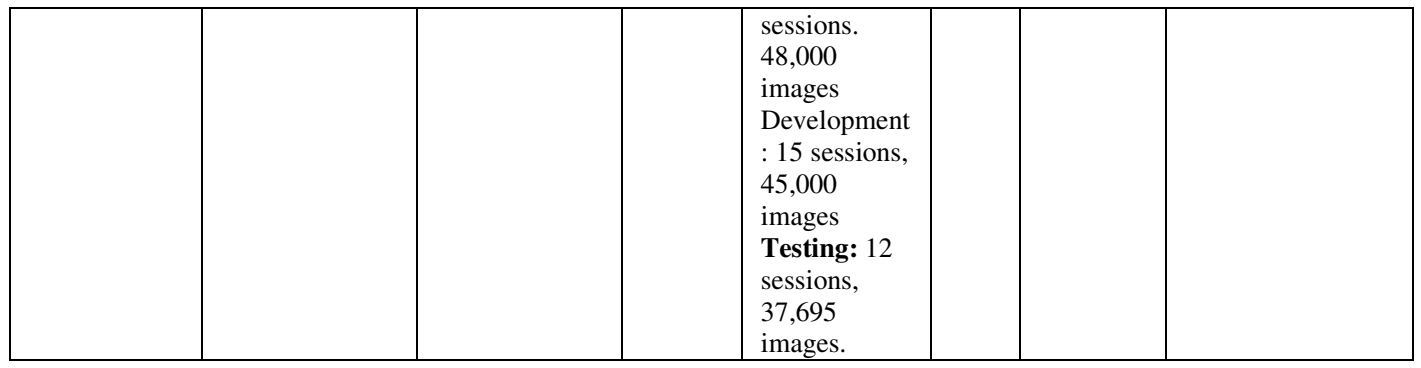

Future efforts in the field of facial and expression recognition may involve identification of expression-based biometrics that can be useful for automated security, surveillance, and identification tracking tasks [77]. Robust automated facial/expression recognition can be used as personal identification systems at grocery stores, travel documentation, banking documentation, examinations and security, and also criminal tracking. Methods that can extract facial informatics from large internet-based data sets can be useful for "Quantitative face" technologies, where every aspect of the face and expression can be mathematically quantified for extremely high resolution information extraction, tracking and monitoring using facial expressions alone.

\section{REFERENCES}

[1] Harmon, Leon D., and Ann B. Lesk. "Identification of human faces." Proceedings of the IEEE 59.5 (1971): 748-760.

[2] Sirovich, Lawrence, and Michael Kirby. "Low-dimensional procedure for the characterization of human faces." JOSA A 4.3 (1987): 519-524.

[3] Turk, Matthew, and Alex P. Pentland. "Face recognition using eigenfaces." IEEE Computer Society Conference on Computer Vision and Pattern Recognition, 1991, pp. 586-591.

[4] Tian, Ying-li, Takeo Kanade, and Jeffrey F. Cohn. "Recognizing action units for facial expression analysis." IEEE Transactions on Pattern Analysis and Machine Intelligence, 23.2 (2001): 97-115.

[5] V. Bettadapura (2012). Face expression recognition and analysis: the state of the art. arXiv preprint arXiv:1203.6722.

[6] National Science and Technology Council, "Face Recognition" [Online].https://www.fbi.gov/aboutus/cjis/fingerprints_biometrics/biometric-center-of-excellence/files/face-recognition.pdf.

[7] University of Notre Dame, "CVRL Data Sets-Biometrics Data Sets," March 2011. [Online]. Available: http://www3.nd.edu/ cvrl/CVRL/Data_Sets.html.

[8] Lucey, Patrick, Jeffrey F. Cohn, Takeo Kanade, Jason Saragih, Zara Ambadar, and Iain Matthews. "The Extended Cohn-Kanade Dataset $(\mathrm{CK}+)$ : A complete dataset for action unit and emotion-specified expression." In IEEE Computer Society Conference on Computer Vision and Pattern Recognition Workshops (CVPRW), 2010, pp. 94-101.

[9] Wechsler, Harry. "Face Recognition Methods for Uncontrolled Settings." Face Recognition in Adverse Conditions (2014): 38.

[10] Phillips, P. J., Flynn, P. J., Scruggs, T., Bowyer, K. W., Chang, J., Hoffman, K., \& Worek, W. Overview of the face recognition grand challenge. In IEEE computer society conference on computer vision and pattern recognition, 2005. Vol. 1, pp. 947-954.

[11] Jafri, Rabia, and Hamid R. Arabnia. "A survey of face recognition techniques." Journal of information processing systems 5.2 (2009): 41-68.

[12] Al-modwahi, Ashraf Abbas M., et al. "Facial expression recognition intelligent security system for real time surveillance." Proc. of World Congress in Computer Science, Computer Engineering, and Applied Computing. 2012.

[13] Lonare, Ashish, and Shweta V. Jain. "A Survey on Facial Expression Analysis for Emotion Recognition." International Journal of Advanced Research in Computer and Communication Engineering 2.12 (2013).

[14] Ekman, P., \& Friesen, W. V. (1971). Constants across cultures in the face and emotion. Journal of personality and social psychology, 17(2), 124.

[15] H.-W. Ng, S. Winkler. A data-driven approach to cleaning large face datasets. Proc. IEEE International Conference on Image Processing (ICIP), Paris, France, Oct. 27-30, 2014.

[16] "The Database of Faces," AT\&T Laboratories Cambridge, (2002). [Online]. Available: http://www.cl.cam.ac.uk/research/dtg/attarchive/facedatabase.html. 
[17] Phillips, P. J., Wechsler, H., Huang, J., \& Rauss, P. J. (1998). The FERET database and evaluation procedure for face-recognition algorithms. Image and vision computing, 16(5), 295-306.

[18] Libor Spacek. (2008) "Description of the Collection of Facial Images". [Online] http://cswww.essex.ac.uk/mv/allfaces/index.html

[19] N.I.S.T."NIST Special Database 18". [Online]http://www.nist.gov/srd/nistsd18.cfm

[20] Messer, K., Matas, J., Kittler, J., Luettin, J., \& Maitre, G. (1999, March). XM2VTSDB: The extended M2VTS database. In Second international conference on audio and video-based biometric person authentication (Vol. 964, pp. 965-966).

[21] Martinez, A. M. (1998). The AR face database. CVC Technical Report, 24.

[22] Georghiades, A. "Yale face database." Center for computational Vision and Control at Yale University, http://cvc.cs.yale.edu/cvc/projects/yalefaces/yalefaces.html (2002).

[23] Computational Visions Group. "Faces 1999". [Online] http://www.vision.caltech.edu/htmlfiles/archive.html

[24] Lyons, Michael, Shota Akamatsu, Miyuki Kamachi, and Jiro Gyoba. "Coding facial expressions with gabor wavelets." In Third IEEE International Conference on Automatic Face and Gesture Recognition, 1998. Proceedings. pp. 200-205.

[25] Hasan, Md Kamrul, and Christopher J. Pal. "Improving alignment of faces for recognition." In IEEE International Symposium on Robotic and Sensors Environments (ROSE), 2011, pp. 249-254.

[26] Wolf, L., Hassner, T., \& Maoz, I. (2011, June). Face recognition in unconstrained videos with matched background similarity. In IEEE Conference on Computer Vision and Pattern Recognition (CVPR), 2011 (pp. 529-534).

[27] Chen, C., Dantcheva, A., \& Ross, A. (2013, June). Automatic facial makeup detection with application in face recognition. In International Conference on Biometrics (ICB), 2013 (pp. 1-8).

[28] Setty, S., Husain, M., Beham, P., Gudavalli, J., Kandasamy, M., Vaddi, R. \& Jawahar, C. V. (2013, December). Indian Movie Face Database: A benchmark for face recognition under wide variations. In IEEE 2013 Fourth National Conference on Computer Vision, Pattern Recognition, Image Processing and Graphics (NCVPRIPG), (pp. 1-5).

[29] Baocai, Y., Yanfeng, S., Chengzhang, W., \& Yun, G. (2009). BJUT-3D Large Scale 3D Face Database and Information Processing. Journal of Computer Research and Development, 6, 020.

[30] Moreno, A. B., and A. Sanchez. "GavabDB: a 3D face database." In Proc. 2nd COST275 Workshop on Biometrics on the Internet, Vigo (Spain), pp. 75-80. 2004.

[31] "Morphace-Basel Face Model Data," Universitat Basel, [Online]. Available: http://faces.cs.unibas.ch/bfm/main.php?nav=1-0\&id=basel_face_model.

[32] M. I. P. Group, "EURECOM Sophia Antipolis-EURECOM Kinect Face Database," EURECOM Institute, September 2014. [Online]. Available: http://rgb-d.eurecom.fr/.

[33] Phillips, P. Jonathon, Patrick J. Flynn, Todd Scruggs, Kevin W. Bowyer, Jin Chang, Kevin Hoffman, Joe Marques, Jaesik Min, and William Worek. "Overview of the face recognition grand challenge." In IEEE computer society conference on Computer vision and pattern recognition, vol. 1, pp. 947-954. IEEE, 2005.

[34] Colombo, Alessandro, Claudio Cusano, and Raimondo Schettini. "UMB-DB: A database of partially occluded 3D faces." In 2011 IEEE International Conference on Computer Vision Workshops (ICCV Workshops), pp. 2113-2119.

[35] Goh, Rodney, et al. "The CMU face in action (FIA) database." Analysis and Modelling of Faces and Gestures. Springer Berlin Heidelberg, 2005. pp 255-263.

[36] Yin, Lijun, Xiaozhou Wei, Yi Sun, Jun Wang, and Matthew J. Rosato. "A 3D facial expression database for facial behavior research." In IEEE 7th international conference on face and gesture recognition, 2006, pp. 211-216.

[37] Faltemier, T.C.; Bowyer, K.W.; Flynn, P.J.; Using a Multi-Instance Enrollment Representation to Improve 3D Face Recognition, Proc. First IEEE International Conference on Biometrics: Theory, Applications, and Systems, September 2007, pp. 1-6.

[38] Xu, Chenghua, Stan Li, Tieniu Tan, and Long Quan. "Automatic 3D face recognition from depth and intensity Gabor features." Pattern Recognition 42, no. 9 (2009): 1895-1905.

[39] Department of Computer Science, "The 3D Face Database," The University of York, [Online]. Available: http://www-users.cs.york.ac.uk/nep/research/3Dface/tomh/3DFaceDatabase.html

[40] MIT Center for Biological and Computational Learning. CBCL face database [Online] http://cbcl.mit.edu/software-datasets/heisele/facerecognition-database.html

[41] Conde, Cristina, and Angel Serrano. "3D facial normalization with spin images and influence of range data calculation over face verification." In IEEE Computer Society Conference on Computer Vision and Pattern Recognition-Workshops, 2005, pp. 115-115.

[42] Brandenburg University of Technology, "The Large MPI Facial Expression Database", March 2014. [Online] http://www.tu-cottbus.de/fakultaet1/en/graphical-systems/forschung/datenbanken/the-large-mpifacial-expression-database.html 
International Journal of Computer Science \& Engineering Survey (IJCSES) Vol.6, No.5, October 2015

[43] Gupta, Shalini, Kenneth R. Castleman, Mia K. Markey, and Alan C. Bovik. "Texas 3D face recognition database." In IEEE Southwest Symposium on Image Analysis \& Interpretation (SSIAI), 2010, pp. 97-100.

[44] Sim, Terence, Simon Baker, and Maan Bsat. "The CMU pose, illumination, and expression (PIE) database." In Fifth IEEE International Conference on Automatic Face and Gesture Recognition, 2002, pp. 46-51.

[45] Savran, Arman, Neşe Alyüz, Hamdi Dibeklioğlu, Oya Çeliktutan, Berk Gökberk, Bülent Sankur, and Lale Akarun. "Bosphorus database for 3D face analysis." In Biometrics and Identity Management, 2008, pp. 4756.

[46] Wechsler, Harry, Jonathon P. Phillips, Vicki Bruce, Francoise Fogelman Soulie, and Thomas S. Huang, eds. Face recognition: From theory to applications. Vol. 163. Springer Science \& Business Media, 2012.

[47] Equinox Corporation "Equinox Face Database". Biometric Consortium Conference 2002. [Online] http://www.biometrics.org/bc2002/1_bc0046_WolffBrief.pdf

[48] Grgic, Mislav, Kresimir Delac, and Sonja Grgic. "SCface-surveillance cameras face database." Multimedia tools and applications 51, no. 3 (2011): 863-879.

[49] Jain, Vidit, and Amitabha Mukherjee. "The indian face database (2002)." [Online] http://vis-www. cs. umass. edu/vidit/IndianFaceDatabase.

[50] Jesorsky, Oliver, Klaus J. Kirchberg, and Robert W. Frischholz. "Robust face detection using the hausdorff distance." In Audio-and video-based biometric person authentication, 2001, pp. 90-95. [Online] https://www.bioid.com/About/BioID-Face-Database

[51] Xiaoyang Tan; Songcan Chen; Jun Li; Zhi-Hua Zhou, "Learning Non-Metric Partial Similarity Based on Maximal Margin Criterion," in IEEE Computer Society Conference on Computer Vision and Pattern Recognition, 2006, vol.1, no., pp.168-145.

[52] Qingshan Liu; Wang Yan; Hanqing Lu; Songde Ma, "Occlusion Robust Face Recognition with Dynamic Similarity Features," in International Conference on Pattern Recognition, 2006. 18th, vol.3, no., pp.544547.

[53] Oh, H. J., Lee, K. M., Lee, S. U., \& Yim, C. H. (2006). Occlusion invariant face recognition using selective LNMF basis images. In Computer Vision-ACCV 2006 (pp. 120-129). Springer Berlin Heidelberg.

[54] Kim, T. Y., Lee, K. M., Lee, S. U., \& Yim, C. H. (2007). Occlusion invariant face recognition using twodimensional PCA. In Advances in Computer Graphics and Computer Vision (pp. 305-315). Springer Berlin Heidelberg.

[55] Zhang, Wenchao, Shiguang Shan, Xilin Chen, and Wen Gao. "Local Gabor binary patterns based on Kullback-Leibler divergence for partially occluded face recognition." Signal Processing Letters, IEEE 14, no. 11 (2007): 875-878.

[56] Lin, Jie, Ji Ming, and Danny Crookes. "A probabilistic union approach to robust face recognition with partial distortion and occlusion." In IEEE International Conference on Acoustics, Speech and Signal Processing, 2008, pp. 993-996.

[57] Guo, Guodong, Stan Z. Li, and Kap Luk Chan. "Support vector machines for face recognition." Image and Vision computing 19, no. 9 (2001): 631-638.

[58] Jia, Hongjun, and Ana Milena Martinez. "Support vector machines in face recognition with occlusions." In IEEE Conference on Computer Vision and Pattern Recognition, 2009, pp. 136-141.

[59] Lin, Jie, Ji Ming, and Danny Crookes. "Robust face recognition with partially occluded images based on a single or a small number of training samples." In IEEE International Conference on Acoustics, Speech and Signal Processing, 2009. pp. 881-884.

[60] Wright, J., Yang, A. Y., Ganesh, A., Sastry, S. S., \& Ma, Y. (2009). Robust face recognition via sparse representation. IEEE Transactions on Pattern Analysis and Machine Intelligence, 31(2), 210-227.

[61] RoyChowdhury, Aruni, et al. "Face Identification with Bilinear CNNs." arXiv preprint arXiv:1506.01342 (2015).

[62] Viola, P., \& Jones, M. (2001). Robust real-time object detection. International Journal of Computer Vision, 4, 51-52.

[63] Hemalatha, G., \& Sumathi, C. P. (2014). A Study of Techniques for Facial Detection and Expression Classification. International Journal of Computer Science \& Engineering Survey (IJCSES) Vol, 5.

[64] Tan, Xiaoyang, Songcan Chen, Zhi-Hua Zhou, and Fuyan Zhang. "Recognizing partially occluded, expression variant faces from single training image per person with SOM and soft k-NN ensemble." IEEE Transactions on Neural Networks, 16, no. 4 (2005): 875-886

[65] Gundimada, S., \& Asari, V. K. (2009). Facial recognition using multisensor images based on localized kernel eigen spaces. IEEE Transactions on Image Processing, 18(6), 1314-1325.

[66] Xue, Mingliang, Wanquan Liu, and Ling Li. "The Uncorrelated and Discriminant Colour Space for Facial Expression Recognition." In Optimization and Control Techniques and Applications, pp. 167-177. Springer Berlin Heidelberg, 2014.

[67] CurtinFaces database. [Online] http://impca.curtin.edu.au/downloads/datasets.cfm 
[68] Saeed, Anwar, Ayoub Al-Hamadi, Robert Niese, and Moftah Elzobi. "Frame-based facial expression recognition using geometrical features." Advances in Human-Computer Interaction 2014: 4.

[69] Sun, Yi, and Lijun Yin. "Facial expression recognition based on 3D dynamic range model sequences." In Computer Vision-ECCV 2008, pp. 58-71. Springer Berlin Heidelberg.

[70] Valstar, M., J. Girard, T. Almaev, Gary McKeown, Marc Mehu, Lijun Yin, Maja Pantic, and J. Cohn. "Fera 2015-second facial expression recognition and analysis challenge." Proc. IEEE ICFG (2015).

[71] X. Zhang, L. Yin, J. F. Cohn, C. S., M. Reale, A. Horowitz, and J. M. Girard. Bp4d-spontaneous: a highresolution spontaneous 3d dynamic facial expression database. Image and Vision Computing, 32(10):692706, 2014.

[72] G. McKeown, M. Valstar, R. Cowie, M. Pantic, and M. Schroder. The semaine database: Annotated multimodal records of emotionally colored conversations between a person and a limited agent. IEEE Transactions on Affective Computing, 3:5-17, 2012.

[73] Dago-Casas, P., González-Jiménez, D., Yu, L. L., \& Alba-Castro, J. L. (2011, November). Single-and cross-database benchmarks for gender classification under unconstrained settings. In IEEE International Conference on Computer Vision Workshops (ICCV Workshops), (pp. 2152-2159).

[74] Beham, M. P., \& Roomi, S. M. (2014). Face Recognition under Uncontrolled Conditions: A Compact Dictionary based Approach. Journal of Imaging Science and Technology, 58(5), 50505-1.

[75] Sarode, J.P.; Anuse, A.D., "A framework for face classification under pose variations," in International Conference on Advances in Computing, Communications and Informatics, vol., no., pp.1886-1891, 24-27 Sept. 2014

[76] Kumar, V., Namboodiri, A. M., \& Jawahar, C. V. Face Recognition in Videos by Label Propagation. In 22nd International Conference on Pattern Recognition (ICPR), 2014 (pp. 303-308).

[77] Thorat, S. B., Nayak, S. K., \& Dandale, J. P. (2010). Facial recognition technology: An analysis with scope in India. arXiv preprint arXiv:1005.4263.

\section{AUTHORS}

Sohini Roychowdhury received her $\mathrm{Ph} . \mathrm{D}$. in Electrical and Computer Engineering from University of Minnesota in August 2014 and M.S. from Kansas State University in May 2010. She is currently an assistant professor in the Department of Electrical Engineering at University of Washington, Bothell. Her research interests include image processing, signal processing, pattern recognition, machine learning, artificial intelligence, low power system design and cloud computing. She is the recipient of two best paper awards, one best poster award and one best paper finalist at the Institute of Engineering and

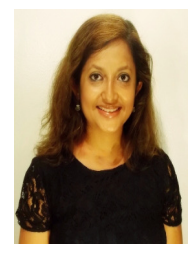
Medicine Conference (2013), IEEE Asilomar Signals, Systems and Computers Conference (2012), IEEE Student Paper Contest Alborg University (2007) and Osmosis Student Paper Contest (2006), respectively. Her online screening system for images with Diabetic Retinopathy (DReAM: Diabetic Retinopathy Analysis Using Machine learning) was featured as the Cover article of the IEEE Journal on Biomedical and Health Informatics in September 2014. She is also the winner of the Graduate School Fellowship for the year 2010 and numerous travel grants, at the University of Minnesota.

Michelle L. Emmons Michelle Emmons received her Bachelor of Science in Electrical Engineering from the University of Washington after attending the Bothell campus in 2015. She served as an avionics technician in the United States Navy. Her military background motivated her interest in Facial and Expression Recognition as a topic of undergraduate research project.

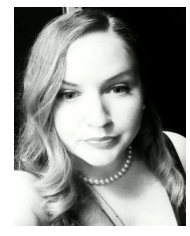

